\title{
Role of anti-CCP in arthritis in patients with systemic lupus erythematosus
}

\author{
Seyedeh Tahereh Faezi, Pedram Paragomi*, Mahmood Akbarian, Seyed Arash Tehrani Banihashemi, Bahar \\ Sadeghi, Farhad Shahram, Ahmad Reza Jamshidi, Farhad Gharibdoost, Abdolhadi Naji, Maasoumeh Akhlaghi \\ and Fereydoun Davatchi \\ Rheumatology Research Center, Tehran University of Medical Sciences (TUMS), Shariati Hospital, Kargar Avenue, Tehran, Iran
}

\begin{abstract}
Systemic lupus erythematosus (SLE) is an autoimmune disease with multi-organ involvement. Patients with SLE feature a lower tendency to develop erosive arthritis in comparison with rheumatoid arthritis (RA); however, in some arthritis cases it may be difficult to differentiate SLE from RA. Anti-cyclic citrullinated peptide (Anti-CCP) antibodies are highly-specific for RA. The current study evaluated the relationship between anti-CCP and arthritis in SLE patients. In this study, anti-CCP antibodies were tested in 300 patients with SLE. The INOVA Diagnostics QUANTA Lite ${ }^{\mathrm{TM}}$ CCP IgG ELISA and the AxisShield Diagnostics Diastat ${ }^{\mathrm{TM}}$ anti-CCP ELISA test were applied. Patients were divided into two groups: those with and those without arthritis. Patients with chronic arthritis ( $>6$ weeks) had radiography done on the involved joints. Chi square and Fisher's exact tests were applied to compare the two subsets. Anti-CCP antibodies were detected in $4.7 \%$ of all patients (CI: 2.6-7.8). Anti-CCP was positive in $6.4 \%$ of patients with arthritis and $2.3 \%$ of patients without arthritis $(P=0.09)$. From seven patients with chronic arthritis, one had both positive anti-CCP and erosions. In the studied Iranian SLE patients, anti-CCP levels were higher in patients with arthritis than in those without arthritis. This study did not show any association of anti-CCP with erosion in SLE patients with arthritis. Ethnic and geographical variance may have influenced the results. More studies on chronic arthritis in SLE are needed to confirm this hypothesis.
\end{abstract}

Keywords: anti-CCP, arthritis, arthropathy, systemic lupus erythematosus.

\section{Introduction}

Systemic lupus erythematosus (SLE) is an autoimmune disease with multi-organ involvement. Arthritis is one of the major clinical findings in SLE reported in up to $90 \%$ of patients [1-4]. Similar to other diseases such as rheumatoid arthritis (RA), arthritis has a considerable effect on disease burden and imperils quality of life [5, 6]. The majority of arthritis lesions in SLE are nonerosive and non-deforming [7, 8]; however, there is a tendency to develop erosion in RA arthritis [9]. In less than $5 \%$ of SLE patients, erosive arthritis develops; this is known as rhupus [10-12]. Erosive arthritis in SLE has a prognosis and clinical course similar to that of RA [13]. The risk factors for the development of erosive arthritis are not fully understood. Recent studies have challenged the concept of non-erosive arthropathy featured in SLE. In some cases with erosive lesions, it may be difficult to differentiate SLE from RA, and many SLE cases are initially misdiagnosed as having RA [14, 15]. Erosive lesions more strongly debilitate and affect the quality of life in SLE patients [16]. Regarding the difference in particular outcomes, it is helpful to use a serological marker to distinguish them at the onset of disease.

Anti-cyclic citrullinated peptide (anti-CCP) antibodies are highly specific and sensitive measures in RA diagnosis and predict the prognosis of disease [17]. Moreover, in a number of non-RA inflammatory conditions such as SLE, positive Anti-CCP is detectable, which demands careful interpretation [18, 19]. A number of previous studies have proposed an association between anti-CCP and erosive or deforming arthritis in SLE and related complications [20-22]. However, the association is not adequately addressed in the literature. The current study evaluated the prevalence of anti-CCP various subsets in SLE patients.

\section{Materials and Methods}

The clinical records of 300 patients visited between January 2006 and February 2007 were studied. The studied population comprised 300 SLE patients (271 females and 29 males). This demographic study was conducted in the connective tissue diseases unit of the Rheumatology Research Center, Tehran University of

* Corresponding Author: Pedram Paragomi, Email: pedram.paragomi@gmail.com, Tel: +98-21-88026956

Received: 07 December 2016; Accepted: 15 March 2017 
Medical Sciences (TUMS). It was approved by the TUMS Ethical Committee. This study was conducted in accordance with the ethical principles outlined in the World Medical Association Declaration of Helsinki.

Patients who fulfilled the American College of Rheumatology (ACR) criteria for SLE were eligible to be enrolled in the current study. The availability of clinical records and radiological exams were other inclusion criteria. Patients with concurrent comorbidities which warranted additional treatment were not eligible to participate in the study.

Data regarding recent complete blood count (CBC), erythrocyte sedimentation rate (ESR), C-reactive protein (CRP), rheumatoid factor (RF), anti-dsDNA, fluorescent antinuclear antibody (FANA), complement component 3 (C3), complement component 4 (C4), complement total hemolytic (CH50), anti-cardiolipin ( $\mathrm{IgG}, \operatorname{IgM}$ ), creatinine, urine analysis U/A, and urine protein were extracted from the participants' files.

Ten milliliters $(\mathrm{ml})$ of whole blood was collected from each participant, and anti-CCP antibodies were measured using enzyme-linked immunosorbent assays (ELISA) (first generation anti-CCP1-test; Euroimmun, Lübeck, Germany). An anti-CCP level > $5 \mathrm{RU} / \mathrm{mL}$ was considered positive. Recent clinical and laboratory findings such as alopecia, leucopenia, photosensitivity, discoid rash, anemia, thrombocytopenia, and raised creatinine $(>1 \mathrm{mg} / \mathrm{dL})$ from the patients' files were studied.

Patients with chronic arthritis (more than 6 weeks) had radiography performed on the involved joints to detect the presence of erosive arthritis.

To address the correlation between anti-CCP and arthritis, patients were divided into two groups, those with and those without arthritis. Patient serum levels of anti-CCP and other data were compared in the two subgroups.

\section{Statistical methods}

Chi square and Fisher's exact test were applied to compare the two subsets. A p-value less than 0.05 was considered statistically significant. All statistical analyses were carried out with the SPSS software, version 21 (Chicago, IL, USA).

\section{Results}

The demographic and clinical characteristics of patients with SLE are shown in Table 1. Positive anti-CCP was detected in 14 out of 300 patients (4.7\%, CI: 2.6-7.8). All anti-CCP positive patients were female. In patients with positive anti-CCP, the mean level was 33.96 RU/mL. There was no statistically significant difference in age, gender, or disease duration between the antiCCP positive and negative subgroups (Table 2).

Arthritis was present in 170 SLE patients (56.7\%). From SLE patients with arthritis, 163 patients $(95.9 \%)$ had transient arthritis, and $7(4.1 \%)$ had chronic arthritis.

Table 1. Demographic, clinical and paraclinical characteristics of studied patients

\begin{tabular}{|c|c|c|}
\hline & $\begin{array}{c}\text { Anti-CCP } \\
\text { positive } \\
\text { subgroup } \\
(\mathrm{N}=14)\end{array}$ & $\begin{array}{c}\text { All } \\
\text { Patients } \\
(\mathbf{N}=\mathbf{3 0 0})\end{array}$ \\
\hline Duration of disease (years) & 5.7 & 6.34 \\
\hline Female & $14(100)$ & 271(90.3) \\
\hline Mean age (years) & 35.1 & 31.59 \\
\hline Arthritis & $10(71.5)$ & $170(56.7)$ \\
\hline Chronic Arthritis (6 weeks) & $1(7)$ & $7(2.5)$ \\
\hline CNS Involvement (history) & $1(7)$ & $38(12.7)$ \\
\hline Renal Involvement (history) & $3(21.4)$ & $124(41.3)$ \\
\hline Photosensitivity (Recent) & $4(28.6)$ & $105(35)$ \\
\hline Malar Rash (Recent) & 0 & $29(9.7)$ \\
\hline Oral Ulcer (Recent) & $2(14.3)$ & $23(7.7)$ \\
\hline Discoid Rash (Recent) & 0 & $12(4)$ \\
\hline Alopecia (Recent) & $3(21.4)$ & $49(16.3)$ \\
\hline Arthritis (Recent) & 0 & $25(8.3)$ \\
\hline Leukopenia $(\mathrm{WBC}<4000)$ & $1(7)$ & $51(17)$ \\
\hline Anemia $(\mathrm{Hb}<10 \mathrm{mg} / \mathrm{dl})$ & $3(21.4)$ & $40(13.3)$ \\
\hline Thrombocytopenia & 0 & $16(5.4)$ \\
\hline Creatinie $>1$ & $1(7)$ & $15(5)$ \\
\hline Increased ESR & $8(57.1)$ & $148(49.3)$ \\
\hline Positive CRP & $2(14.3)$ & $50(16.6)$ \\
\hline Positive RF & $2(14.3)$ & $18(6)$ \\
\hline Positive FANA & $7(50)$ & $120(40)$ \\
\hline Positive Anti-ds DNA & $6(42.9)$ & $115(38.3)$ \\
\hline Positive anti-Cardiolipin (Ig G) & $1(7)$ & $24(8)$ \\
\hline Positive anti-Cardiolipin (Ig M) & $1(7)$ & $21(7)$ \\
\hline Low C3 & $2(14.3)$ & $62(20.7)$ \\
\hline Low $\mathrm{C} 4$ & $1(7)$ & $50(16.7)$ \\
\hline Low CH50 & $1(7)$ & $24(8)$ \\
\hline Proteinuria $<3500 \mathrm{mg} / 24$ hours & $3(21.4)$ & $44(14.6)$ \\
\hline Proteinuria $>3500 \mathrm{mg} / 24$ hours & 0 & $5(16)$ \\
\hline Low dose prednisolone $<15 \mathrm{mg} /$ day & $198(66)$ & $12(85.7)$ \\
\hline $\begin{array}{l}\text { Moderate dose prednisolone } \\
15<<30 \mathrm{mg} \text { /day }\end{array}$ & $47(15.7)$ & $1(7)$ \\
\hline High dose prednisolone $30<\mathrm{mg} /$ day & $25(8.3)$ & $1(7)$ \\
\hline Hydroxychloroquin & $210(70)$ & $9(64.3)$ \\
\hline Methotrexate & $16(5.3)$ & $4(28.6)$ \\
\hline Azathioprine & $49(16.3)$ & $4(28.6)$ \\
\hline Cyclophosphamide & $35(11.7)$ & 0 \\
\hline Cellcept & $10(3.3)$ & 0 \\
\hline Cyclosporine & $2(0.7)$ & 0 \\
\hline Overlap with Scleroderma & $4(1.4)$ & $1(7)$ \\
\hline $\begin{array}{l}\text { Overlap with Polymyositis/ } \\
\text { Dermatomyositis }\end{array}$ & $4(1.4)$ & 0 \\
\hline
\end{tabular}

Rheum. Res., Vol. 2, No. 3, Jul. 2017 
Table 2. The relation of anti-CCP with sex, age, and duration of disease

\begin{tabular}{lccc}
\hline & $\begin{array}{c}\text { Positive } \\
\text { anti-CCP } \\
(\mathbf{N = 1 4 )}\end{array}$ & $\begin{array}{c}\text { Negative } \\
\text { anti-CCP } \\
(\mathbf{N = 2 8 6})\end{array}$ & $\boldsymbol{P}$ value \\
\hline Female & $14(100 \%)$ & $257(89.9 \%)$ & 0.34 \\
Male & 0 & $29(10.1)$ & \\
Age (year) & $35.07 \pm 13.02$ & $31.41 \pm 10.42$ & 0.207 \\
Duration of disease & $5.71 \pm 3.38$ & $6.36 \pm 6.57$ & 0.516 \\
\hline
\end{tabular}

Positive anti-CCP was noted in 11 patients with arthritis $(6.5 \%)$ and 3 patients of the non-arthritis subset $(2.3 \%)$. The difference in anti-CCP positivity between the two subgroups was not statistically significant $(P$ value $=0.09) \quad($ Table 3$)$. Mean anti-CCP titer was $39.35 \pm 15.05 \mathrm{RU} / \mathrm{mL}($ mean \pm S.E) in patients with arthritis and $14.23 \pm 4.72 \mathrm{RU} / \mathrm{mL}($ mean \pm S.E) in those without arthritis $(P$-value $=0.41)$.

Table 3. The relation of Anti CCP with Arthritis and its characteristics

\begin{tabular}{lccc}
\hline & & $\begin{array}{c}\text { Positive anti-CCP } \\
\text { N=14 } \\
\text { Number }(\%)\end{array}$ & P value \\
\hline Arthritis & Yes $(\mathrm{n}=170)$ & $11(6.4)$ & 0.090 \\
Chronic & Yes $(\mathrm{n}=130)$ & $3(2.3)$ & \\
Arthritis & No $(\mathrm{n}=163)$ & $1(14.3)$ & 0.391 \\
Erosion & Yes $(\mathrm{n}=1)$ & $10(6.1)$ & 0.143 \\
\hline
\end{tabular}

Eleven arthritis cases with positive anti-CCP comprised 10 cases of transient arthritis and one of chronic arthritis. The patient with chronic arthritis had erosive joint damage confirmed by $\mathrm{x}$-ray imaging (Table 3). The prevalence rate of anti-CCP positivity among chronic arthritis cases was (14.3\%), while $6.1 \%$ of transient arthritis cases were anti-CCP positive (Table 3).

Positive RF was reported in two patients with positive anti-CCP (14.3\%). RF-positive cases included one patient with transient arthritis and one with chronic arthritis. There was a significant relationship between anti-CCP and RF in this study $(P=0.004)$.

The anti-CCP-positive subgroup had a higher rate of anti-ds DNA and FANA. However, in comparison with the total studied group, low complement levels were less frequent in anti-CCP-positive cases.

\section{Discussion}

The concept of non-erosive lupus arthropathy has recently been challenged by innovative radiological techniques. Some studies have postulated that erosive arthritis develops in a higher percentage of SLE patients $[23,24]$. However, this debilitating complication has not been amply discussed in the literature. The underlying pathogenesis of erosive arthritis is not fully understood [11]. The predictive value of serological markers in the development of specific lupus complications such as erosive arthritis has been the subject of an ongoing dispute [20]. A review article by Budhram et al. revealed anti-CCP as a predictor of erosive arthritis in SLE [25]. There is growing evidence that suggests a higher prevalence of anti-CCP expression in rhupus in comparison with SLE patients [26]. However, SLE patients with deforming arthropathy demonstrate clinical features comparable to cases of rhupus [27]. Lower levels of complement components (C3, C4, and CH50) were less common among anti-CCP-positive cases in comparison with the whole cohort. This notion may be partly due to the limited number of anti-CCPpositive cases in this study.

The prevalence rate of anti-CCP positivity in sera in this study was similar to that in some previous reports $[28,29]$. The prevalence rate of positive anti-CCP and the level of antibody expression were higher in the arthritis subset than in the non-arthritis subset; however, the difference was not statistically significant. This might result from the small number of patients with positive anti-CCP.

Radiographic evaluation of patients with chronic arthritis showed erosive arthritis in only one patient. This patient was the only case with positive anti-CCP among all chronic arthritis cases. The current study did not demonstrate any significant association between anti-CCP positivity and the development of erosive arthritis in the SLE population. This result was in contrast with those of a number of previous studies which have indicated a meaningful association between anti-CCP and erosive arthritis in SLE patients [13, 29]. This lack of association must be cautiously interpreted. The limited number of enrolled patients, the small number of cases with chronic arthritis, and specifically the single case of erosive arthritis may have partially affected the results. Qing et al. have proposed the role of ethnic and geographical variance in the expression of anti-CCP antibodies in SLE patients [21]. Similarly, ethnic and geographical variance may have influenced the results of the current study.

A significant association between serum RF levels and anti-CCP positivity was observed in SLE patients. This finding was similar to previously-described findings in patients with rheumatoid arthritis $[10,11$, 
12, 13, 21-23]. In contrast, another study of SLE, rhupus, and RA has negated the significant association between anti-CCP levels and erosive or non-erosive arthropathy [27].

Overall, erosive arthritis was confirmed in only one patient of the current study population. Larger studies on SLE patients are warranted to show a possible correlation between anti-CCP and erosive arthritis.

The current study had a number of limitations, namely, the small sample size and the lack of therapeutic information on arthritis.

\section{Conclusion}

This study did not show any association of anti-CCP with erosion in SLE patients with arthritis. Future longitudinal studies are needed to further investigate the correlation between erosive arthritis and anti-CCP positivity in SLE.

\section{Conflict of interest}

The authors declare no conflicts of interest.

\section{Acknowledgments}

The authors would like to thank the patients who confided in us for their cooperation with this study.

\section{References}

1. Zoma A. Musculoskeletal involvement in systemic lupus erythematosus. Lupus 2004; 13(11): 851-3. doi: 10.1191/ 09612033031u2021oa.

2. Wright S, Filippucci E, Grassi W, Grey A, Bell A. Hand arthritis in systemic lupus erythematosus: an ultrasound pictorial essay. Lupus 2006; 15(8): 501-6. doi: 10.1191/ 0961203306lu2340oa.

3. Aptekar RG, Lawless OJ, Decker JL. Deforming non-erosive arthritis of the hand in systemic lupus erythematosus. Clin Orthop Relat Res 1974; 100(5): 120-4. doi: 197405000-00018.

4. Molinari JA. Handwashing and hand care: fundamental asepsis requirements. Compend Contin Educ Dent 1995; 16(9): 834, 6.

5. Ball EM, Bell AL. Lupus arthritis--do we have a clinically useful classification? Rheumatology (Oxford) 2012; 51(5): 771-9. doi: 10.1093/ rheumatology/ker381.

6. Fonseca R, Aguiar F, Rodrigues M, Brito I. Clinical phenotype and outcome in lupus according to age: a comparison between juvenile and adult onset. Reumatologia Clinica 2016. doi: 10.1016/j.reuma.2016.10.011.

7. Pipili C, Sfritzeri A, Cholongitas E. Deforming arthropathy in systemic lupus erythematosus. European J Internal Medicine 2008; 19(7): 482-7. doi: 10.1016/ j.ejim.2008.01.017.

8. Pipili C, Sfritzeri A, Cholongitas E. Deforming arthropathy in SLE: review in the literature apropos of one case. Rheum International 2009; 29(10): 1219-21. doi: 10.1007/s00296-008-0780-8.

9. Ogura T, Hirata A, Hayashi N, Takenaka S, Ito H, Mizushina K, et al. Comparison of ultrasonographic joint and tendon findings in hands between early, treatment-naive patients with systemic lupus erythematosus and rheumatoid arthritis. Lupus 2016: 961203316676375. doi: $10.1177 /$ 0961203316676375.

10. van Vugt RM, Derksen RH, Kater L, Bijlsma JW. Deforming arthropathy or lupus and rhupus hands in systemic lupus erythematosus. Ann Rheum Dis 1998; 57(9): 540-4. doi: 10.1136/ard.57.9.540.

11. Martinez JB, Valero JS, Bautista AJ, Restrepo JF, Matteson EL, Rondon F, et al. Erosive arthropathy: clinical variance in lupus erythematosus and association with anti-CCP case series and review of the literature. Clin Exp Rheumatol 2007; 25(1): 47-53.

12. Richter Cohen M, Steiner G, Smolen JS, Isenberg DA. Erosive arthritis in systemic lupus erythematosus: analysis of a distinct clinical and serological subset. Br J Rheumatol 1998; 37(4): 421-4. doi: 10.1093/rheumatology/37.4.421.

13. Mediwake R, Isenberg DA, Schellekens GA, van Venrooij WJ. Use of anti-citrullinated peptide and anti-RA33 antibodies in distinguishing erosive arthritis in patients with systemic lupus erythematosus and rheumatoid arthritis. Ann Rheum Dis 2001; 60(1): 67-8. doi: 10.1136/ard.60. 1.67.

14. Vitali C, Bencivelli W, Isenberg DA, Smolen JS, Snaith ML, Sciuto M, et al. Disease activity in systemic lupus erythematosus: report of the Consensus Study Group of the European Workshop for Rheumatology Research. II. Identification of the variables indicative of disease activity and their use in the development of an activity score. The European Consensus Study Group for Disease Activity in SLE. Clin Exp Rheumatol 1992; 10(5): 541-7.

15. Alarcon-Segovia D. Deforming arthropathy of the hands in SLE and the growing pains of MCTD. J Rheumatol. 1991; 18(4): 632.

16. Taraborelli $M$, Inverardi $F$, Fredi M, Ceribelli A, Cavazzana I, Tincani A, et al. Anti-cyclic citrullinated peptide antibodies in systemic lupus erythematosus patients with articular involvement: a predictive marker for erosive disease? Reumatismo 2012; 64(5): 321-5. doi: 10.4081/ reumatismo.2012.321.

17. Suzuki K, Sawada T, Murakami A, Matsui T, Tohma S, Nakazono $\mathrm{K}$, et al. High diagnostic performance of ELISA detection of antibodies to citrullinated antigens in rheumatoid arthritis. Scand J Rheumatol 2003; 32(4): 197-204. doi: 10.1080/ 03009740310003677.

18. Vannini A, Cheung K, Fusconi M, Stammen-Vogelzangs J, Drenth JP, Dall'Aglio AC, et al. 
Anti-cyclic citrullinated peptide positivity in non-rheumatoid arthritis disease samples: citrulline-dependent or not? Ann Rheum Dis 2007; 66(4): 511-6. doi: 10.1136/ard.2006.058933.

19. Labrador-Horrillo $M$, Martinez MA, Selva-O'Callaghan A, Delgado JF, Martinez-Gomez X, Trallero-Araguas E, et al. Anticyclic citrullinated peptide and anti-keratin antibodies in patients with idiopathic inflammatory myopathy. Rheum (Oxford) 2009; 48(6): 676-9. doi: 10.1093/rheumatology/kep065.

20. Zhao Y, Li J, Li XX, Li C, Li L, Li ZG. What can we learn from the presence of anti-cyclic citrullinated peptide antibodies in systemic lupus erythematosus? Joint Bone Spine 2009; 76(5): 501-7. doi: 10.1016/j.jbspin.2008. 11.007.

21. Qing YF, Zhang QB, Zhou JG, Yuan GH, Wei J, Xing Y, et al. The detecting and clinical value of anti-cyclic citrullinated peptide antibodies in patients with systemic lupus erythematosus. Lupus 2009; 18(8): 713-7. doi: 10.1177/0961203309102817.

22. Kakumanu P, Sobel ES, Narain S, Li Y, Akaogi J, Yamasaki Y, et al. Citrulline dependence of anticyclic citrullinated peptide antibodies in systemic lupus erythematosus as a marker of deforming/erosive arthritis. $\boldsymbol{J}$ Rheumatol 2009; 36(12): 268290. doi: 10.3899/jrheum.090338.

23. Boutry N, Hachulla E, Flipo RM, Cortet B, Cotten A. MR imaging findings in hands in early rheumatoid arthritis: comparison with those in systemic lupus erythematosus and primary Sjogren syndrome. Radiology 2005; 236(2): 593-600. doi: 10. 1148/radiol.2361040844.

24. Ostendorf B, Scherer A, Specker C, Modder U, Schneider M. Jaccoud's arthropathy in systemic lupus erythematosus: differentiation of deforming and erosive patterns by magnetic resonance imaging. Arthritis and Rheumatism 2003; 48(1): 157 65. doi: 10.1002/art.10753.

25. Budhram A, Chu R, RustaSallehy S, Ioannidis G, Denburg JA, Adachi JD, et al. Anti-cyclic citrullinated peptide antibody as a marker of erosive arthritis in patients with systemic lupus erythematosus: a systematic review and meta-analysis. Lupus 2014; 23(11): 1156-63. doi:
$10.1177 / 0961203314540967$.

26. Amezcua-Guerra LM, Springall R, Marquez-Velasco R, GomezGarcia L, Vargas A, Bojalil R. Presence of antibodies against cyclic citrullinated peptides in patients with 'rhupus': a crosssectional study. Arthritis Research \& Therapy 2006; 8(5): R144.

27. Damian-Abrego G, Cabiedes J, Cabral A. Anti-citrullinated peptide antibodies in lupus patients with or without deforming arthropathy. Lupus 2008; 17(4): 300-4. doi: 10.1177/ 0961203307087613.

28. Damian-Abrego GN, Cabiedes J, Cabral AR. Anti-citrullinated peptide antibodies in lupus patients with or without deforming arthropathy. Lupus 2008; 17(4): 300-4. doi: 10.1177/ 0961203307087613.

29. Hoffman IE, Peene I, Cebecauer $\mathrm{L}$, Isenberg $\mathrm{D}$, Huizinga $\mathrm{TW}$, Union A, et al. Presence of rheumatoid factor and antibodies to citrullinated peptides in systemic lupus erythematosus. Ann Rheum Dis 2005; 64(2): 330-2. doi: 10.1136/ard.2004. 022111. 